\title{
Concepções de professoras sobre suas práticas pedagógicas utilizando o tipo textual narrativo antes e após um programa de intervenção metatextual
}

\author{
Ana Paula Zaboroski* \\ Jáima Pinheiro Oliveira** \\ Aliandra Cristina Mesomo Lira***
}

\section{Resumo}

Este artigo teve como objetivo identificar, na concepção das professoras, suas práticas pedagógicas desenvolvidas com o tipo textual narrativo antes e após um programa de intervenção metatextual. Participaram do estudo duas professoras e 27 alunos do $4^{\circ}$ ano do Ensino Fundamental de duas escolas públicas municipais do interior do estado do Paraná. A pesquisa colaborativa e propositiva foi composta por cinco etapas: a) investigação de práticas pedagógicas das professoras utilizando o tipo textual narrativo; b) avaliação do esquema de narrativa escrita pelos alunos; c) realização de encontros com as professoras para estudo do tema e de uma proposta de intervenção; d) intervenção na prática pedagógica voltada à produção de narrativas escritas pelos alunos; e) avaliação do esquema de narrativa escrita pelos alunos e da prática pedagógica proposta. A coleta de dados consistiu em entrevistas semiestruturadas e individuais realizadas com as professoras. As entrevistas foram transcritas e analisadas por meio de seus conteúdos, estabelecendo-se categorias temáticas. Os resultados indicaram que a ausência de domínio da estrutura e da organização do tipo textual narrativo interferia no planejamento das estratégias pedagógicas. As práticas pedagógicas desenvolvidas eram voltadas ao uso da linguagem, enfatizando os aspectos normativos da gramática. Após o desenvolvimento do programa, as práticas direcionaram seu foco para a reflexão sobre a língua e a linguagem, abrangendo instruções explícitas sobre a produção do tipo textual narrativo. Concluímos que uma intervenção educacional planejada e breve favorece a prática pedagógica voltada para a produção de narrativas escritas mais elaboradas e completas pelos alunos.

Palavras-chave: Aprendizagem da escrita. Prática pedagógica. Assessoria às escolas.

\footnotetext{
* Mestra em Educação pela Universidade Estadual do Centro-Oeste (UNICENTRO), campus de Guarapuava/PR.

*** Doutora em Educação pela Faculdade de Filosofia e Ciências da Universidade Estadual Paulista Júlio de Mesquita Filho (UNESP). Professora do Departamento de Educação Especial da Universidade Estadual Paulista Júlio de Mesquita Filho (UNESP), campus de Marília/SP.
}

\footnotetext{
**** Doutora em Educação pela Universidade de São Paulo (USP). Professora do Departamento de Pedagogia da Universidade Estadual do Centro-Oeste (UNICENTRO), campus de Guarapuava/PR.
}

PERSPECTIVA, Florianópolis, v. 35, n. 3, p.784-802 jul./set. 2017

http://www.perspectiva.ufsc.br 


\section{Introdução}

Os dados do Programa Internacional de Avaliação de Alunos (PISA) revelaram que os estudantes não são capazes de deduzir informações do texto, de estabelecer relações entre diferentes partes do texto e não conseguem compreender nuances da linguagem (PISA, 2012). As dificuldades presentes no processo de escolarização são advindas de inúmeros fatores; entre eles, encontramos os individuais, familiares, socioeconômicos e educacionais.

Diante deste contexto, a problematização do nosso artigo envolveu questões sobre a prática pedagógica com o uso do tipo textual narrativo em produções escritas pelos alunos do Ciclo I do Ensino Fundamental, suscitando os seguintes questionamentos: quais são as práticas pedagógicas desenvolvidas, no contexto de sala de aula, para trabalhar o tipo textual narrativo? Uma intervenção educacional planejada e breve favorece a prática pedagógica voltada à produção de narrativas escritas?

No estudo realizado por Zaboroski e Oliveira (2015) as autoras apresentaram um panorama das pesquisas publicadas acerca das práticas pedagógicas desenvolvidas no processo de ensino da produção textual conto (história) com alunos do Ciclo I do Ensino Fundamental. A revisão sistemática foi efetuada a partir da busca por artigos no Portal de Periódicos da Coordenação de Aperfeiçoamento de Pessoal de Nível Superior (Capes), no período entre 2004 e 2014. Por meio da análise de conteúdo, os estudos foram distribuídos em quatro categorias temáticas.

Os resultados da análise de 21 estudos indicaram que houve predominância em duas categorias: desenvolvimento de sequências didáticas ou programas de intervenções e estratégias pedagógicas utilizadas no processo de ensino da produção textual. As intervenções em produções de narrativas escritas priorizaram atividades individuais desenvolvidas com os alunos. As sequências didáticas enfatizaram o papel dos gêneros textuais como objeto de ensino-aprendizagem ou consideraram as dimensões dos elementos que os compõem.

Em relação às estratégias pedagógicas, constataram-se dois enfoques: estratégias direcionadas para práticas pedagógicas voltadas à norma e ao texto e estratégias voltadas à noção de gêneros textuais, especificamente para o reconhecimento dos aspectos discursivos e linguísticos. As autoras concluíram que as pesquisas apontaram para a necessidade e a importância da instrução explícita no processo de ensino da produção textual. Além disso, o foco das pesquisas, até o momento, volta-se para atividades desenvolvidas com os alunos. Desta forma, verificou-se uma lacuna na literatura quanto ao desenvolvimento de programas de ensino ou intervenção com foco no trabalho do professor em sala de aula que favoreçam as produções de narrativas escritas pelos alunos.

Algumas pesquisas demonstraram as concepções dos professores sobre as práticas pedagógicas voltadas à produção de narrativas escritas. Os estudos desenvolvidos por Pinton (2011), Araújo (2011) e Assolini (2008) evidenciaram estratégias pedagógicas e condições de produção inadequadas para o trabalho com a produção textual narrativa, direcionadas exclusivamente aos aspectos da norma e do texto. Estas estratégias se constituíram em uma orientação metodológica para a produção de textos narrativos, envolvendo atividades normativas para a reescrita do texto, enfatizando os aspectos gramaticais, como a pontuação e a ortografia, bem como atividades voltadas para a reprodução de 
modelos de textos literários. Por outro lado, outras pesquisas expuseram estratégias pedagógicas que envolveram o trabalho com a noção de gêneros textuais, especificamente para o reconhecimento dos aspectos discursivos e linguísticos relevantes no gênero a ser trabalhado, para transpô-los didaticamente (DALLA-BONA; BUFREM, 2013; BARROS; PADILHA, 2011).

Estes estudos enfatizaram o papel do professor como responsável por instigar a reflexão dos alunos sobre a escrita e criar as condições pedagógicas para que escrevam com prazer, autonomia e criatividade. Baseadas nos resultados de pesquisas publicadas sobre estratégias pedagógicas favoráveis à produção de histórias, Rodrigues e Vilela (2012) alertaram para a importância da realização de adaptações escolares. Também mencionaram o planejamento de atividades sistematizadas, as quais devem propiciar aos alunos a reflexão sobre a estrutura e a organização de uma história. Araújo (2011) concluiu que o desempenho dos alunos nas atividades de produção de texto depende da qualidade do ensino com texto, pelo texto e sobre o texto.

Algumas pesquisas indicaram como apoio para o desenvolvimento da habilidade de produção narrativa escrita a exploração da consciência metatextual (REGO, 1996; ALBUQUERQUE; SPINILLO, 1998; ZABOROSKI, 2014; OLIVEIRA; ZABOROSKI, 2015). Outra maneira de auxiliar essa habilidade é o uso de figuras em sequência, ou seja, a utilização do apoio visual (LINS-SILVA; SPINILLO, 2000). Outras pesquisas enfatizam o uso do texto narrativo com foco voltado para a intervenção metatextual com crianças que apresentam dificuldades de aprendizagem (FERREIRA; CORREIA, 2008; OLIVEIRA; BRAGA, 2009; OLIVEIRA, 2010).

O conhecimento metalinguístico é apenas um dos inúmeros aspectos envolvidos no processo de ensino-aprendizagem da linguagem escrita (leitura e escrita). Esse conhecimento está relacionado às atividades que envolvem a atenção consciente aos aspectos formais da linguagem, em que algumas unidades linguísticas podem ser adotadas para reflexão. Isso é o que define os diferentes tipos de habilidades metalinguísticas: fonológica, morfológica, sintática, pragmática e metatextual. Desse modo, a consciência metatextual considera o texto como unidade de análise (GOMBERT, 1992). Portanto, o nosso artigo enfatizou os aspectos macrolinguísticos da consciência metatextual, remetendo-se às convenções linguísticas e aos elementos que estruturam e organizam o gênero textual conto (histórias). Ressaltamos que a história é constituída por mais de um tipo textual, a saber: descritivo, narrativo e explicativo. Contudo, por apresentar uma sucessão temporal/causal de eventos, entre os quais ocorre algum tipo de modificação de um estado de coisas e configura na presença do enredo, há o predomínio em sua constituição do tipo textual narrativo (KOCH; ELIAS, 2010), foco do nosso artigo.

Desta forma, nosso estudo se propôs a identificar, na concepção das professoras, as práticas pedagógicas voltadas ao tipo textual narrativo desenvolvidas por elas antes e após a realização de um programa de intervenção metatextual.

\section{Aspectos metodológicos}

\subsection{Aspectos éticos}

A pesquisa respeitou todas as normas estabelecidas pela Resolução 466/2012, referente aos aspectos éticos em pesquisas com seres humanos e foi aprovada pelo Comitê de Ética em Pesquisa da Universidade Estadual do Centro-Oeste (Unicentro), sob o protocolo de no 487.650, no ano de 2013. 


\subsection{Participantes e Local da pesquisa}

Fizeram parte desta pesquisa duas professoras e 27 alunos do $4^{\circ}$ ano do Ensino Fundamental de duas escolas públicas rurais municipais de uma cidade do interior do Estado do Paraná.

\subsubsection{Perfil das professoras}

Apresentamos, na Tabela 1, os dados referentes à formação, ao tempo de atuação e experiência das professoras com o $4^{\circ}$ ano do Ensino Fundamental:

Tabela 1: Dados das professoras referentes à formação e à atuação profissional

\begin{tabular}{c|c|c|c|c|c|c}
\hline Professora & Idade & Gênero & $\begin{array}{c}\text { Educação } \\
\text { Básica }\end{array}$ & $\begin{array}{c}\text { Ensino superior } \\
\text { e Pós-Graduação }\end{array}$ & $\begin{array}{c}\text { Tempo de } \\
\text { atuação }\end{array}$ & $\begin{array}{c}\text { Atuação } \\
\text { com alunos } \\
\text { do 4 40 ano }\end{array}$ \\
\hline $\mathbf{1}$ & 45 & Feminino & Magistério & $\begin{array}{c}\text { Pedagogia; } \\
\text { Especialização em } \\
\text { Arte, Educação e } \\
\text { Terapia }\end{array}$ & 18 anos & 4 anos \\
$\mathbf{2}$ & 43 & Feminino & Magistério & $\begin{array}{c}\text { Pedagogia } \\
\text { anos }\end{array}$ & 21 anos & 2 anos \\
\hline
\end{tabular}

Fonte: Elaborado pelas pesquisadoras.

Em relação à formação profissional, as professoras possuem o Magistério, a nível do Ensino Médio e graduação em Pedagogia. A Professora 1 possui Pós-Graduação Lato Sensu em Arte, Educação e Terapia.

\subsection{Caracterização do estudo e procedimentos para coleta e análise dos dados}

O estudo foi caracterizado por uma pesquisa colaborativa e propositiva (LIEBERMAN, 1986) com a finalidade exploratória e descritiva (GIL, 2007). A pesquisa foi composta por cinco etapas: a) investigação da prática pedagógica com o uso do tipo textual narrativo; b) avaliação do esquema de narrativa escrita pelos alunos referente à estrutura e à organização do texto; c) realização de encontros com as professoras para estudo do tema e elaboração de uma proposta de intervenção; d) intervenção na prática pedagógica voltada à produção de narrativas escritas pelos alunos; e e) avaliação do esquema de narrativa escrita pelos alunos e da prática pedagógica proposta por meio do programa de intervenção.

Os procedimentos utilizados para a coleta de dados consistiram em entrevistas semiestruturadas e individuais realizadas com as professoras. Primeiramente, as entrevistas consideraram quais as atividades com o tipo textual narrativo eram desenvolvidas com os alunos e de que forma eram abordadas pelas professoras durante a prática pedagógica na disciplina de Língua Portuguesa. Após o desenvolvimento do programa de intervenção metatextual, a pesquisadora novamente realizou 
entrevistas com as professoras, abordando os aspectos em relação aos encontros para estudo e às práticas educacionais propostas por meio do programa de intervenção.

As entrevistas foram gravadas e transcritas posteriormente. Os dados envolveram a análise de conteúdo por meio de categorias temáticas, as quais foram estabelecidas pela pesquisadora, com base em Bardin (2011). Primeiramente, definimos as categorias, conceituando-as de acordo com a temática a elas relacionada. E, posteriormente, apresentamos a categorização das unidades de análise. Os dados foram apresentados por meio de quadros.

O programa de intervenção metatextual foi conduzido pelas professoras, e a sequência didática foi composta por cinco módulos, envolvendo duas atividades com toda a turma, semanalmente, durante as aulas da disciplina de Língua Portuguesa. Na atividade 1, foram utilizadas histórias tradicionais (contos) para identificação dos elementos da narrativa escrita em relação à estrutura e à organização do texto (consciência metatextual). $\mathrm{Na}$ atividade 2, foram utilizadas figuras em sequência (apoio visual) para a produção de narrativas escritas. Cada módulo englobou ambas as atividades.

\section{Resultados e Discussão}

Apresentamos, por meio de quadros, primeiramente os dados referentes ao conhecimento e às práticas pedagógicas desenvolvidas pelas professoras com o tipo textual narrativo. Em seguida, os dados acerca das práticas educacionais propostas por meio do programa de intervenção metatextual.

\subsection{Concepções das professoras referentes às práticas pedagógicas desenvolvidas no cotidiano que abordam o tipo textual narrativo}

a) Conhecimentos referentes ao tipo textual narrativo: esta categoria se refere aos relatos das professoras que articularam os conhecimentos que possuíam sobre o tipo textual narrativo, especificamente voltado ao gênero textual conto;

Quadro 1: conhecimentos relatados referentes ao tipo textual narrativo

\begin{tabular}{|c|c|c|}
\hline Professoras & Relatos & Ideias subjacentes \\
\hline P1 & $\begin{array}{l}\text { (...) a gente não pode começar falando diretamente no assunto, } \\
\text { tem que dar uma entrada e fazer a sequência normal da } \\
\text { história e a finalização dela. Tem que ter o local, os } \\
\text { personagens da história. Então, isso eu acho que tem que } \\
\text { entrar logo no início. Depois vem o que acontece. Aí é o que } \\
\text { eu coloco pra eles sempre é (...) um assunto vai emendando no } \\
\text { outro e cuidar pra não fazer a repetição dos assuntos pra daí a } \\
\text { finalização. }\end{array}$ & \multirow{2}{*}{$\begin{array}{l}\text { Conhecimento do } \\
\text { gênero textual conto } \\
\text { (história) voltado ao } \\
\text { conceito de início, } \\
\text { meio e fim. }\end{array}$} \\
\hline $\mathrm{P} 2$ & $\begin{array}{l}\text { Sequência lógica, se a história tem uma sequência (...) Que } \\
\text { tem aquele começo, o meio e o fim. }\end{array}$ & \\
\hline
\end{tabular}

Fonte: Elaborado pelas pesquisadoras.

Constatamos que o conhecimento que as professoras possuíam acerca do gênero textual conto (história) se referia ao conceito de início, meio e fim. Ambas também relataram a necessidade de a 
história apresentar uma sequência, contudo não fizeram menção aos elementos que compõem o gênero textual conto (cenário, tema, enredo e resolução), os quais, nesta ordem, configuram a sequência da história. Apenas a Professora 1 descreveu os elementos que compõem o cenário, porém não especificou os demais elementos presentes na história. Dessa forma, identificamos que as professoras dominavam pouco a estrutura e a organização deste gênero textual.

Há autores que mencionam na definição do texto narrativo os conceitos de início, meio e fim. Todavia, descrevem os elementos que constituem cada um destes aspectos, os quais estruturam e organizam a história (SPINILLO; MARTINS, 1997). Araújo (2011) enfatiza que o uso de um determinado gênero textual como instrumento de ensino somente pode ser concebido a partir do momento em que este é conhecido pelo professor, uma vez que, para o processo de ensino, é imprescindível conhecer os aspectos sociocomunicativos que o caracterizam.

b) Estratégias pedagógicas voltadas à produção de texto: esta categoria se refere aos relatos das professoras que articularam as estratégias pedagógicas utilizadas no cotidiano, na disciplina de Língua Portuguesa, para a produção de textos pelos alunos;

Quadro 2: estratégias pedagógicas voltadas à produção de texto

\begin{tabular}{|c|c|c|}
\hline Professoras & Relatos & Ideias subjacentes \\
\hline \multirow[t]{2}{*}{ P1 } & $\begin{array}{l}\text { (...) eu normalmente todos os dias, em certos momentos eu } \\
\text { deixo eles (alunos) à vontade pra eles lerem (...). Eles } \\
\text { escolhem o livro que eles querem, eles lêem o que eles } \\
\text { querem (...) eles vão lá e pegam umas adivinhações. Livros de } \\
\text { vez em quando eu peço pra eles é..., hoje vocês vão pegar } \\
\text { fábulas. } \\
\text { (...) primeiro a gente faz um estudo do que é a fábula ou } \\
\text { qualquer outro tipo textual um convite, um bilhete. Eu procuro } \\
\text { conversar sobre o assunto primeiro, pra eles entenderem o que } \\
\text { eles vão fazer, o que é aquele tipo de texto, porque se chama } \\
\text { receita, fábula, ... adivinhas. } \\
\text { Ah, eu leio, eu trago exemplos pra eles. (...) Por exemplo uma } \\
\text { fábula, eu leio duas, três fábulas pra eles entenderem } \\
\text { exatamente o que é uma fábula. (...) pra eles terem uma ideia } \\
\text { de como que se descreve. (...) vocês têm que pensar que tem } \\
\text { que ter um começo, um meio e um fim (...). } \\
\text { Reprodução de histórias, produções ... às vezes eu faço assim } \\
\text { oh, vocês vão escolher um tema como título e a partir desse } \\
\text { tema vocês vão desenvolver a produção. } \\
\text { É... pensem em frases, frases que depois possam montar um } \\
\text { texto. Cada um dá a sua parte naquele texto, vamos formar um } \\
\text { texto só. Em grupos cada um escreve uma frase ou duas e } \\
\text { depois juntos montam o texto. É ... mais ou menos isso. }\end{array}$ & 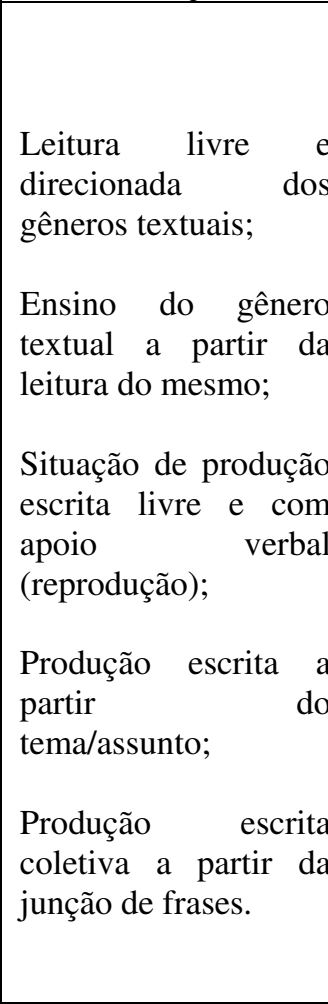 \\
\hline & $\begin{array}{l}\text { A gente dá um tema/assunto ou uma gravura para eles } \\
\text { escreverem lá sobre uma história. É uma única gravura, mas } \\
\text { tem gravura em sequência também. Às vezes, (...) eu também } \\
\text { peço para os alunos mudarem o final da história. Então, (...) } \\
\text { eles estão reescrevendo a história e não criando um texto. }\end{array}$ & \begin{tabular}{|l} 
Produção escrita a \\
partir \\
tema/assunto;
\end{tabular} \\
\hline
\end{tabular}




\begin{tabular}{|c|c|c|}
\hline P2 & $\begin{array}{l}\text { Na produção de texto eu estava trabalhando a formação de } \\
\text { frases. A gente coloca a figura de um palhaço e lá no final } \\
\text { uma cartola, a gente espera que eles escrevam: "O palhaço } \\
\text { gosta de usar uma cartola bonita". Eu acho que a partir do } \\
\text { momento que eles começam a formar frases mais criativas, } \\
\text { favorece a escrita de histórias porque escrevendo frases como: } \\
\text { "A casa é bonita", "O cachorro é bonito"...aí na hora de } \\
\text { produção de texto não vai sair mesmo. } \\
\text { (...) eu dou o texto pronto e eles vão vendo o desenho e } \\
\text { completando as frases. (...) tem lá a figura de um coelho que } \\
\text { estava subindo uma escada e ele cai, e daí tem as perguntas: O } \\
\text { coelho estava subindo na......aí eles completam: escada. Sabe, } \\
\text { são textos bem simples, mas eu achei a necessidade de } \\
\text { trabalhar porque eu acho que com isso eles vão tendo essa } \\
\text { noção de começo, meio e fim. Depois os alunos reescrevem } \\
\text { este texto no caderno. Só que acaba acontecendo que eles } \\
\text { escrevem a mesma história, acabam copiando as frases, eles } \\
\text { não elaboram um texto com as frases e também não } \\
\text { modificam. }\end{array}$ & $\begin{array}{l}\text { Situação de produção } \\
\text { escrita com apoio } \\
\text { visual (figuras); } \\
\text { Reformulação do } \\
\text { final da história; } \\
\text { Sintaxe; } \\
\text { Completar frases no } \\
\text { texto; } \\
\text { Reescrita/cópia do } \\
\text { texto; } \\
\begin{array}{l}\text { Necessidade } \\
\text { trabalhar diversidade } \\
\text { de gêneros e tipos } \\
\text { textuais. }\end{array}\end{array}$ \\
\hline
\end{tabular}

Fonte: Elaborado pelas pesquisadoras.

Os relatos das professoras demonstraram que algumas estratégias pedagógicas voltadas à produção de texto pelos alunos ocorriam em ambas as turmas, sendo elas: produção escrita a partir da sugestão de um tema/assunto, produção escrita livre, bem como a produção a partir de um apoio verbal ou visual. Outros três aspectos nos chamaram a atenção. O primeiro diz respeito ao fato de a Professora 2, em sua concepção, considerar que, para os alunos melhorarem o desempenho em suas produções textuais, evidenciando sequência em suas histórias, seria preciso trabalhar a sintaxe: “[...] a partir do momento que eles (alunos) começam a formar frases mais criativas, favorece a escrita de histórias [...]”, afirmou. Essa concepção direciona as atividades dos alunos à estruturação de frases, como a estratégia de completar frases no texto e, em seguida, reescrevê-lo. Todavia, a professora constatou que os alunos não conseguiam elaborar uma narrativa a partir das frases, realizando apenas a cópia das referidas frases do texto. Apesar de a Professora 1 não enfatizar a sintaxe em suas estratégias pedagógicas, entre as atividades desenvolvidas com a turma, ocorria a produção escrita coletiva a partir da junção de frases.

Algumas pesquisas, semelhantes ao nosso estudo, também identificaram estratégias pedagógicas e condições de produção escrita, nas quais se trabalhava com: proposição de temas artificiais; pouco ou nenhum acompanhamento por parte do professor e ausência de instruções explícitas nas várias etapas de elaboração do texto; práticas pautadas no ensino da gramática tradicional, com frases isoladas ou com exemplos retirados dos livros didáticos (ARAÚJO, 2011; PINTON, 2011; ASSOLINI, 2008). Esta forma de refletir sobre a língua se distancia de uma abordagem de língua enquanto sistema de comunicação, conforme é preconizado pelos Parâmetros 
Curriculares Nacionais (PCN) da Língua Portuguesa para o Ensino Fundamental, os quais prestigiam unidades linguísticas mais amplas, como o texto ${ }^{1}$ (BRASIL, 1998).

$\mathrm{O}$ segundo aspecto se refere ao fato de a Professora 1 utilizar, entre suas estratégias pedagógicas, a leitura livre e direcionada de alguns gêneros textuais. Entretanto o ensino desses gêneros, no que diz respeito à estrutura e à organização dos elementos que os compõem, restringe-se ao conhecimento e à sua identificação por meio de manipulação de portadores de texto. As autoras Barros e Padilha (2011) destacaram esta atividade como uma das estratégias pedagógicas utilizadas para a compreensão do gênero textual. Contudo enfatizaram que, nesta etapa, é feita uma descrição cuidadosa dos aspectos formais e de conteúdo do gênero textual, situação esta que não foi identificada em nossa pesquisa.

Nos Parâmetros Curriculares Nacionais (PCN), especificamente para o ensino de Língua Portuguesa, são estabelecidos dois eixos. O primeiro enfoca o uso da linguagem por meio das práticas de escuta, leitura e produção de textos orais e escritos, e o segundo a reflexão sobre a língua e a linguagem, abrangendo aspectos ligados à variação linguística; à organização estrutural dos enunciados; aos processos de construção da significação; ao léxico e às redes semânticas; e aos modos de organização dos discursos (BRASIL, 1998). Considerando o exposto, constatamos que a prática pedagógica está voltada ao primeiro eixo para o ensino da língua, ou seja, ao uso da linguagem.

$\mathrm{O}$ terceiro aspecto diz respeito ao fato de a Professora 2 ter recebido instruções da pedagoga sobre a necessidade de considerar em suas estratégias pedagógicas a diversidade dos gêneros e tipos textuais. Porém percebemos que não está clara para as professoras a diferença entre gêneros e tipos textuais. Este resultado corrobora o encontrado por Araújo (2011).

Constatamos que o pouco domínio da estrutura e da organização dos gêneros textuais, neste caso especificamente o conto (história), interfere no planejamento das estratégias pedagógicas, insuficientes e, algumas vezes, até inadequadas para o processo de ensino-aprendizagem dos referidos gêneros e produções textuais. As estratégias pedagógicas voltadas à produção de texto eram fundamentadas no ensino da gramática e seus componentes. Sendo assim, valorizavam os aspectos normativos e formais da escrita, evidenciando a concepção de que a aprendizagem requer o ensino da gramática, no tocante aos padrões sintáticos e às regras ortográficas. Também identificamos a ausência de instruções explícitas sobre a produção do gênero conto (história), bem como de qualquer outro gênero textual. Reforçamos que esta aprendizagem ocorre apenas por meio do ensino formal em sala de aula (GOMBERT, 2013; 1992).

Sendo assim, problematizamos a formação destas professoras. Que tipo de formação está sendo dada a ponto de uma pessoa diplomar-se em uma profissão regulamentada sem conhecer apropriadamente o conteúdo, a dimensão e as possibilidades de atuação que ela oferece? Como os aspectos do desenvolvimento infantil, o ensino das habilidades de leitura e de escrita e a formação do leitor/escritor estão sendo apresentados e discutidos nos cursos de formação dos professores, de forma a possibilitar e garantir o desenvolvimento integral e intelectual dos alunos? Nossa intenção não é apenas culpabilizar o professor mas também refletir sobre a qualidade da formação inicial e, consequentemente, compreender as práticas de ensino utilizadas com os alunos em sala de aula. 
c) Aspectos considerados na avaliação das produções textuais dos alunos: esta categoria se refere aos relatos das professoras que relacionaram os aspectos por elas considerados na avaliação das produções textuais dos alunos, especificamente do gênero textual conto (história);

Quadro 3: aspectos considerados na avaliação das produções textuais dos alunos

\begin{tabular}{|c|l|l|}
\hline Professoras & \multicolumn{1}{|c|}{ Relatos } & \multicolumn{1}{|c|}{ Ideias subjacentes } \\
\hline P1 & $\begin{array}{l}\text { A ... como que diz, a ... (pausa maior) sequência da história. } \\
\text { Se não há muita repetição de palavras, de frases mesmo. } \\
\text { A pontuação também, mas em primeiro lugar a organização } \\
\text { do texto. Depois vem a paragrafação (...). }\end{array}$ & $\begin{array}{l}\text { Aspectos macro e } \\
\text { microlinguísticos. }\end{array}$ \\
\hline P2 & $\begin{array}{l}\text { A gente começa avaliando a participação deles, desde a } \\
\text { pintura, a criatividade. Sei lá, a gente verifica se a história tem } \\
\text { uma sequência, é sempre isso que a gente avalia. (...) Que tem } \\
\text { aquele começo, o meio e o fim. Geralmente acaba não tendo o } \\
\text { meio e o fim. }\end{array}$ & $\begin{array}{l}\text { Aspectos cognitivos e } \\
\text { macrolinguísticos; } \\
\text { linguísticos nos aspectos } \\
\text { metatextuais. }\end{array}$ \\
\hline
\end{tabular}

Fonte: Elaborado pelas pesquisadoras.

A Professora 1 enfatizou mais a necessidade de considerar, na avaliação das produções textuais dos alunos, os aspectos macrolinguísticos que se referem à organização geral e à estrutura do texto, envolvendo a sequência e a paragrafação. Em seguida, considerou a necessidade dos aspectos microlinguísticos, como a presença da pontuação e da coesão textual. Já a Professora 2, inicialmente considerou alguns aspectos cognitivos, mas revelou dúvida em relação aos aspectos linguísticos e metatextuais que poderiam ser considerados na avaliação das produções textuais. Ao final do seu relato, acabou citando o aspecto macrolinguístico, no que diz respeito à presença da sequência na história.

Contrapondo a situação demonstrada pelas professoras quanto aos aspectos a ser considerados na avaliação das produções textuais dos alunos, os autores Dolz e Gagnon (2010), ao apresentar a noção de gênero textual e a exploração das noções didáticas que dele se originam, constataram que um objeto de ensino-aprendizagem bem delimitado facilita a elaboração de critérios de avaliação. Já a autora Assolini (2008), ao analisar os saberes e fazeres pedagógicos de professores do Ensino Fundamental, referentes às questões que envolvem a produção textual escrita, identificou que os professores se preocupam mais em avaliar e corrigir os erros gramaticais e de grafia que encontram nos textos e menos em valorizar a capacidade dos alunos para compor textos. Os resultados encontrados em nossa pesquisa corroboram os de Assolini (2008), contudo ressaltamos que a Professora 1 enfatizou a preocupação quanto à organização geral e à estrutura do texto.

d) Aspectos que orientam o trabalho com os gêneros textuais: esta categoria se refere aos relatos das professoras sobre os aspectos do Projeto Político Pedagógico (PPP), bem como acerca do método de alfabetização que orientam a prática pedagógica voltada ao gênero textual conto (história); 
Quadro 4: aspectos que orientam o trabalho com os gêneros textuais

\begin{tabular}{|c|l|c|}
\hline Professoras & \multicolumn{1}{|c|}{ Relatos } & Ideias subjacentes \\
\hline P1 & $\begin{array}{l}\text { No momento assim eu não saberia te dizer (...). Ah, a gente } \\
\text { precisa ler bastante, estar bastante atenta ao que pede ali } \\
\text { (referindo-se ao PPP) pra não sair fora (...) é como um } \\
\text { documento a seguir. }\end{array}$ & \\
& $\begin{array}{l}\text { É alguns métodos de ensino que são mais antigos, de maneira } \\
\text { mais tradicional. (...) É hoje em dia já se usa mais a } \\
\text { brincadeira, jogos, ... como que a gente diz ... maneira lúdica } \\
\text { de ensinar. }\end{array}$ & $\begin{array}{c}\text { Desconhecimento dos } \\
\text { aspectos que orientam }\end{array}$ \\
\hline \multirow{5}{*}{ P2 } & $\begin{array}{l}\text { Ai eu acho que eu não vou saber responder essa. Nossa não } \\
\text { faz tempo na V. (se referindo ao momento do início do ano } \\
\text { em que os professores se reuniram em uma escola para } \\
\text { verificar a necessidade de reformulação do PPP) a gente ficou } \\
\text { revendo, lendo, trabalhando em cima, só que agora eu não } \\
\text { estou lembrando dele...(pausa). }\end{array}$ & \\
& $\begin{array}{l}\text { Como assim método? (Pausa longa) ai minha nossa deixa eu } \\
\text { pensar...os métodos... no meu trabalho eu considero muito a } \\
\text { realidade deles (alunos) porque cada um deles é diferente. }\end{array}$ & \\
\hline
\end{tabular}

Fonte: Elaborado pelas pesquisadoras.

Identificamos desconhecimento, por parte das professoras, de aspectos do Projeto Político Pedagógico (PPP) e do método de alfabetização que orientam a prática pedagógica. Esta situação nos conduz à reflexão sobre dois aspectos.

O primeiro diz respeito à participação das professoras na elaboração e/ou reformulação do PPP. Os relatos indicaram que esta participação não ocorreu de maneira efetiva. Entendemos participação efetiva como ação do professor ao se envolver e contribuir com os aspectos do PPP reformulados anualmente. Esta situação nos remete ainda às questões sobre o uso do PPP na escola, a função deste documento neste ambiente e qual documento orienta o trabalho das professoras em sala de aula, especialmente os planejamentos diário ou semanal.

Nos Parâmetros Curriculares Nacionais (PCN), há recomendações curriculares que propõem o ensino da Língua Portuguesa a partir dos gêneros textuais, tomados como objetos de ensinoaprendizagem. Tais recomendações trazem uma mudança de paradigma teórico e metodológico para o ensino de Língua Portuguesa, que, anteriormente, fundamentava-se na gramática normativa (BRASIL, 1998). Constatamos que o desconhecimento das professoras acerca dos aspectos que orientam o trabalho com os gêneros textuais implica práticas pedagógicas que ainda não envolveram essa mudança curricular.

Conforme já citamos anteriormente, o segundo aspecto que nos conduz à reflexão se refere à formação inicial destes profissionais e reforça a necessidade da oferta de formações continuadas em serviço voltadas, principalmente, às questões do processo de ensino-aprendizagem que evidenciam lacunas em sua formação inicial. Algumas pesquisas também apontaram para a importância do desenvolvimento dos processos de formação permanente, visando à reflexão e a transformações nos 
saberes e fazeres pedagógicos, ou seja, nas bases teórico-metodológicas da prática pedagógica (RODRIGUES; VILELA, 2012; BARROS; PADILHA, 2011; ASSOLINI, 2008).

\subsection{Concepções das professoras referentes às práticas pedagógicas após o programa de intervenção metatextual}

e) Contribuições dos encontros de estudo e do programa de intervenção: esta categoria se refere aos relatos das professoras que relacionaram as contribuições dos encontros de estudo para o conhecimento do gênero textual conto (história) e para a sua formação profissional. As professoras também mencionaram as contribuições do programa de intervenção para o processo de produção do tipo textual narrativo pelos alunos;

Quadro 5: contribuições dos encontros de estudo e do programa de intervenção

\begin{tabular}{|c|c|c|}
\hline Professoras & Relatos & Ideias subjacentes \\
\hline P1 & $\begin{array}{l}\text { Então, antes de todo esse trabalho, esse processo de } \\
\text { aprendizagem porque para mim foi uma aprendizagem, era } \\
\text { colocado pra gente que uma história teria o começo, o meio e } \\
\text { o fim. E agora foi complementada com todos aqueles } \\
\text { elementos (professora se refere aos elementos que compõem a } \\
\text { história) que eu acabei aprendendo muito, na verdade. } \\
\text { (...) colocar como início o cenário. Daí o meio que seria o } \\
\text { tema e o enredo. E o final é a resolução. O início lá, que seria } \\
\text { os personagens, o tempo, o lugar (...) O tema, eu não sabia que } \\
\text { é uma situação-problema. (...) eu não sabia que deveria na } \\
\text { história ter um problema (...). E o enredo, como alguém } \\
\text { poderia tentar resolver aquele problema. Eu não tinha essa } \\
\text { ideia que cada elemento poderia ser colocado num parágrafo, } \\
\text { que poderiam surgir mais problemas na história, mais temas, } \\
\text { mais enredo. } \\
\text { Então, eu não sabia como passar para eles (alunos) antes e, } \\
\text { agora, eu estou tendo essa facilidade porque pra mim se } \\
\text { tornou muito mais fácil de ensinar desta maneira. (...) as } \\
\text { crianças acabam entendendo melhor a história. As crianças } \\
\text { seguiram todos esses elementos para começar e terminar (...) } \\
\text { os próprios alunos já conseguem escrever uma história mais } \\
\text { completa. (...) antes nem eles (alunos) mesmos entendiam, não } \\
\text { sabiam de que forma colocar, o que colocar numa produção. } \\
\text { Agora tá mais fácil até pra eles. }\end{array}$ & $\begin{array}{l}\text { Formação inicial; } \\
\text { Formação } \\
\text { permanente; } \\
\text { Estrutura } \\
\text { organização do } \\
\text { gênero textual conto } \\
\text { (história); } \\
\text { Aspecto } \\
\text { macrolinguístico; } \\
\text { Prática pedagógica } \\
\text { voltada ao tipo textual } \\
\text { narrativo; }\end{array}$ \\
\hline $\mathrm{P} 2$ & $\begin{array}{l}\text { Que bom que eu tive a oportunidade de ter estudado e } \\
\text { desenvolvido este trabalho em sala de aula. Pra mim foi muito } \\
\text { bom. (...) } \\
\text { Eu até então, nunca tinha comentado com os meus alunos que } \\
\text { pra eles iniciarem um texto, eles tinham que começar pelo } \\
\text { cenário, colocando os personagens, um determinado lugar, um } \\
\text { tempo. Eu apenas dizia pra eles: "vocês vão fazer um texto } \\
\text { que tenha começo, meio e fim". E daí o tema e o enredo...o } \\
\text { tema eu sempre coloquei como o título: "vocês vão escrever } \\
\text { sobre um tema que seja sobre o meio ambiente", pra mim o } \\
\text { tema era o meio ambiente e não alguma coisa que estava } \\
\text { acontecendo com o meio ambiente, sabe? E lá que o enredo }\end{array}$ & $\begin{array}{l}\text { Aprendizagem do tipo } \\
\text { textual narrativo; } \\
\text { Prática pedagógica } \\
\text { voltada à } \\
\text { diferenciação dos } \\
\text { gêneros textuais. }\end{array}$ \\
\hline
\end{tabular}




\begin{tabular}{|l|l|}
\hline fosse as ações dos personagens para tentar resolver os \\
problemas do texto. \\
Além disso, a importância de trabalhar com eles na produção \\
de textos a diferença entre os textos. Entre o gênero textual \\
história e um outro texto como uma receita. Eu até então, não \\
tinha essa preocupação (...) não colocava para eles que o texto \\
da receita é diferente de um outro gênero textual, sabe? \\
Eu também achei que nas atividades deles (alunos) em sala de \\
aula como melhoraram as produções de textos deles do gênero \\
de história. Hoje eles sabem aquele começo, aquele meio e \\
aquele fim, eles têm noção do que é, o que a gente pede \\
quando eles vão escrever um texto.
\end{tabular} \mid

Fonte: Elaborado pelas pesquisadoras.

As professoras destacaram em seus relatos as lacunas existentes na formação inicial a respeito do conhecimento do gênero textual conto, voltado ao conceito de início, meio e fim. Na concepção das professoras, essas lacunas possibilitaram um processo de ensino-aprendizagem inadequado e insuficiente no que diz respeito ao conhecimento deste gênero textual e à produção escrita pelos alunos.

Todavia as professoras também demonstraram que o desenvolvimento dos estudos e das práticas educacionais propostas por meio do programa de intervenção metatextual contribuiu para a formação permanente, favorecendo a reflexão sobre a formação profissional, a prática pedagógica utilizada e, consequentemente, a aprendizagem dos alunos. As professoras contrapõem, por meio da formação inicial e da formação permanente, a prática pedagógica desenvolvida à aprendizagem dos alunos acerca do gênero textual conto.

Algumas pesquisas evidenciaram reflexões a respeito destes processos de formação profissional (ZABOROSKI; OLIVEIRA, 2014; RODRIGUES; VILELA, 2012; BARROS; PADILHA, 2011; ASSOLINI, 2008). Estas pesquisas enfatizaram que as formações permanentes devem favorecer os saberes e fazeres pedagógicos, ressaltando a importância de o próprio professor, a partir de uma capacitação específica, ministrar as intervenções em sala de aula, desenvolvendo estratégias pedagógicas e condições de produção escrita adequadas.

As professoras demonstraram domínio do conhecimento metatextual ao explicitar os elementos que compõem a história, enfatizando a organização destes elementos no texto, associados ao conceito de início, meio e fim, por meio do aspecto macrolinguístico da paragrafação. Além disso, a Professora 2 também apontou a necessidade de diferenciar, no processo de ensino, a estrutura da organização dos demais gêneros textuais. Esta reflexão demonstra que a professora identificou que cada gênero textual possui suas especificidades quanto aos elementos que os constituem. Notamos também que ela percebeu diferenças entre os conceitos de gênero e tipo textual.

$\mathrm{O}$ desenvolvimento da sequência didática do gênero textual conto (história), junto às professoras, corrobora o exposto pelos autores Dolz e Gagnon (2010). Estes pesquisadores relatam que a elaboração de um modelo didático do gênero textual para ser trabalhado na prática pedagógica supõe a identificação dos elementos que estruturam e organizam o referido gênero textual, os quais direcionam as atividades e as sequências de ensino a serem desenvolvidas. Também mencionam que a instrução explícita acerca das definições destes elementos facilita o processo de ensino-aprendizagem do gênero textual. Esta situação foi identificada em nossa pesquisa após o desenvolvimento dos 
encontros de estudo e das práticas educacionais propostas por meio do programa de intervenção, caracterizando uma ruptura parcial com as práticas pedagógicas de referência.

Considerando o exposto, constatamos que, após o desenvolvimento do programa de intervenção metatextual, as práticas pedagógicas direcionaram seu foco para a reflexão sobre a língua e a linguagem (BRASIL, 1998). Além disso, ressaltamos que a sequência didática elaborada para trabalhar o gênero textual conto (história) a partir do uso de estratégias metatextuais envolveu os quatro eixos de ensino do professor: leitura, análise e reflexão sobre a língua e a linguagem, produção escrita e escuta/produção oral (SÃO PAULO, 2007).

f) Ressignificação do uso e função social da linguagem escrita: esta categoria se refere aos relatos das professoras que relacionaram a compreensão do uso e da função social da escrita, especificamente sobre a produção do tipo textual narrativo.

\begin{tabular}{|c|c|c|}
\hline Professoras & Relatos & Ideias subjacentes \\
\hline $\mathrm{P} 1$ & $\begin{array}{l}\text { (...) eu na verdade no tempo de escola nunca gostei de } \\
\text { produção de texto, fazia porque tinha que fazer. Agora eu } \\
\text { estou vendo por um outro lado, que eu tenho certeza que para } \\
\text { as próprias crianças elas mudaram a visão e o conceito de } \\
\text { história. Porque quando se falava em fazer história elas } \\
\text { diziam: "Ahhh!!!" e agora não!! Então, eles pegam o } \\
\text { caderninho deles que tem o quadro (professora se refere ao } \\
\text { quadro de autorregulação que apresenta os quatro elementos } \\
\text { que compõem uma história) e vão produzindo. Então, pra eles } \\
\text { se tornou mais fácil, se tornou mais prático. Muitos deles já } \\
\text { até decoraram e não precisam mais do auxílio do quadro (de } \\
\text { autorregulação), pois já sabem qual é a sequência da história. }\end{array}$ & \multirow[t]{2}{*}{$\begin{array}{l}\text { Interesse sobre o } \\
\text { texto, a história; } \\
\text { Prazer em escrever. }\end{array}$} \\
\hline $\mathrm{P} 2$ & $\begin{array}{l}\text { Eu achei que eles estão gostando mais de fazer texto porque } \\
\text { agora quando a gente pede pra eles fazerem um texto, nossa } \\
\text { eles já comentam antes qual que vai ser o problema, sabe } \\
\text { assim....agora eles têm noção pra fazer um texto. (...) Agora } \\
\text { eles escrevem com vontade, eu achei que despertou neles mais } \\
\text { o interesse. (...) Eu também estou gostando mais de trabalhar a } \\
\text { produção de texto. }\end{array}$ & \\
\hline
\end{tabular}

Fonte: Elaborado pelas pesquisadoras.

Os relatos demonstraram que houve compreensão a respeito do uso e da função social da escrita, tanto pelas professoras quanto pelos alunos. As práticas educacionais propostas pelo programa de intervenção despertaram nestes sujeitos o interesse pela história. Professoras e alunos adquiriram um prazer em escrever, realizando a atividade da produção textual não mais como algo imposto e obrigatório do processo de escolarização, conforme destaca o relato da Professora 1. Outros estudos também fizeram referência às estratégias pedagógicas e às condições de produção escrita adequadas, que ressignificaram o uso e a função social da leitura e da escrita (DALLA-BONA; BUFREM, 2013; CÁRNIO et al., 2012; BARROS; PADILHA, 2011; ROMANO-SOARES et al., 2010).

Os autores Cárnio et al. (2012) e Romano-Soares et al. (2010) concluíram que o programa de promoção de narrativas escritas, utilizando livros de histórias, auxiliou o professor a trazer a leitura e a 
produção textual para a sala de aula de uma forma reflexiva, discursiva e prazerosa. Desta forma, motivou o hábito de leitura dos alunos e, consequentemente, aprimorou a produção escrita. As autoras Dalla-Bona e Bufrem (2013), Barros e Padilha (2011) demonstraram que estratégias pedagógicas para familiarizar os alunos com as características estruturais e linguísticas dos gêneros literários, assim como promover a interação entre os alunos em sala de aula, de forma que eles possam se posicionar criticamente ao ler, refletir e escrever, propiciaram a aproximação da leitura com a escrita e a aprendizagem do conteúdo literário. A relação do aluno com a escrita deixou de ser meramente escolar. $\mathrm{O}$ aluno encontrou uma finalidade e um sentido para a sua escrita, a partir do momento que esta passou a participar ativamente de uma necessidade comunicativa.

\section{Conclusão}

Nosso artigo se propôs a identificar, na concepção das professoras, as práticas pedagógicas voltadas ao tipo textual narrativo desenvolvidas por elas antes e após a realização de um programa de intervenção metatextual. Constatamos que a ausência de domínio por parte das professoras sobre a estrutura e a organização do tipo textual narrativo interferia em seu planejamento de estratégias pedagógicas. As práticas pedagógicas desenvolvidas eram voltadas ao uso da linguagem, caracterizadas por atividades de escuta, leitura e produção de textos orais e escritos, as quais enfatizavam os aspectos normativos da gramática, considerados como condição essencial para que os alunos pudessem redigir as narrativas. Desse modo, verificamos que as práticas pedagógicas e as condições de produção escrita eram insuficientes e inadequadas para o processo de ensinoaprendizagem do tipo textual narrativo, bem como de sua produção. Além disso, identificamos o desconhecimento das professoras sobre os aspectos do Projeto Político Pedagógico (PPP) e do método de alfabetização que orientam a prática pedagógica.

Após o desenvolvimento das práticas educacionais propostas por meio do programa de intervenção metatextual, as práticas pedagógicas voltaram seu foco para a reflexão sobre a língua e a linguagem, abrangendo instruções explícitas sobre a produção do tipo textual narrativo, como a organização estrutural dos enunciados e os processos de construção da significação. A prática pedagógica, utilizando a sequência didática elaborada para trabalhar o gênero textual conto (história) a partir do uso de estratégias metatextuais, envolveu os quatro eixos de ensino do professor: leitura, análise e reflexão sobre a língua e a linguagem, produção escrita e escuta/produção oral. Portanto podemos afirmar que uma intervenção educacional planejada e breve favorece a prática pedagógica voltada para a produção de narrativas escritas mais elaboradas e completas pelos alunos.

As práticas educacionais propostas por meio do programa de intervenção auxiliaram no desenvolvimento e no domínio da consciência metatextual, tanto para as professoras quanto para os alunos, favorecendo também a reflexão acerca das práticas pedagógicas desenvolvidas. Além disso, despertaram o prazer e o interesse pela produção de narrativas escritas na população estudada, ressignificando o uso e a função social da leitura e da escrita. 
A instrução explícita demonstrou ser um dos fatores importantes para o desenvolvimento da consciência metatextual e do domínio do esquema narrativo. As docentes enfatizaram que a consciência metatextual acerca do gênero textual conto, assim como de qualquer outro gênero textual, revelou uma lacuna em suas formações iniciais e, portanto, o programa de intervenção também contribuiu para a formação continuada em serviço. Sendo assim, sugerimos, para pesquisas futuras, favorecer o processo de ensino-aprendizagem dos demais gêneros textuais a partir de estratégias de ensino que envolvam a consciência metatextual do gênero a ser trabalhado.

\section{Notas}

${ }^{1} \mathrm{O}$ termo texto é definido como uma ocorrência linguística oral ou escrita, de qualquer extensão, dotada de unidade sociocomunicativa, semântica e formal (FÁVERO; KOCH, 2000). 


\section{REFERÊNCIAS}

ALBUQUERQUE, E.B.C.; SPINILLO, A.G. Consciência textual em crianças: critérios adotados na identificação de partes de textos. Revista de Estudios e Investigación en Psicoloxia e Educación, v. 3, 145-158, 1998.

ASSOLINI, F.E.P. Análise discursiva dos saberes e fazeres pedagógicos de professores do ensino fundamental. Alfa, v. 52, n. 1, p. 123-147, 2008.

ARAÚJO, J.J.C. do N. O ensino com gêneros textuais e o letramento em língua materna no Programa de aceleração da aprendizagem Asas da Florestania - Acre.Colloquium Humanarum, v. 8, n. 2, p. 1-8, jul./dez. 2011.

BARDIN, L. Análise de Conteúdo.São Paulo: Edições 70, 2011.

BARROS, C.G.P. de; PADILHA, S. de J. Para uma escrita criadora: da produção de textos à formação de autores. Interacções, n. 19, p. 259-273, 2011.

BRASIL. Parâmetros Curriculares Nacionais (PCNs): $3^{\circ}$ e $4^{o}$ ciclos do Ensino Fundamental - Língua Portuguesa. Brasília/DF: MEC/SEF, 1998.

CÁRNIO, M.S.; ALVES, D.C.; REHEM, L.O.; SOARES, A.J.C. Práticas de narrativas escritas: atuação fonoaudiológica. Revista CEFAC, v. 14, n. 5, p. 792-798, set./out. 2012.

DALLA-BONA, E.M.; BUFREM, L.S. Aluno-autor: a aprendizagem da escrita literária nas séries iniciais do ensino fundamental. Educação em Revista, v. 29, n. 1, p. 179-203, mar. 2013.

DOLZ, J.; GAGNON, R. El género textual, una herramienta didáctica para desarrollar el lenguaje oral y escrito. Tradução: Verónica Sánchez. Lenguaje, v. 38, n. 2, p. 497-527, 2010.

FÁVERO, L.L.; KOCH, I.G.V. Linguística textual: Introdução. São Paulo: Cortez, 2000.

FERREIRA, S. P.; CORREIA, J. A influência de diferentes contextos de intervenção na escrita de histórias por crianças. Estudos de Psicologia, Campinas, v. 25, n. 4, p. 547-555, 2008.

GIL, A.C. Como elaborar projetos de pesquisa. 4. ed. São Paulo: Atlas, 2007.

GOMBERT, J.E. Epi/meta versus implícito/explícito: nível de controle cognitivo sobre a leitura e sua aprendizagem. In: MALUF, M.R.; CARDOSO-MARTINS, C. (Orgs.). Alfabetização no século XXI: Como se aprende a ler e escrever. Porto Alegre: Penso, 2013.p.109-123.

GOMBERT, J.E. Metalinguistic development. Harvester: Wheatsheaf, 1992.

KOCH, I.V.; ELIAS, V.M. Ler e escrever: estratégias de produção textual. 2. ed. São Paulo: Contexto, 2010.

LIEBERMAN, A. Collaborative research: Working with, not working on... Educational Leadership, v. 43, n. 5, p. 29-32, 1986. 
LINS-SILVA, M. E.; SPINILLO, A. G. A influência de diferentes situações de produção na escrita de histórias. Psicologia: Reflexão e Crítica, v.13, n.3, p.337-350, 2000.

OLIVEIRA, J. P. Efeitos de um programa de intervenção metatextual em escolares com dificuldades de aprendizagem. 2010. 138f. Tese (Doutorado em Educação) - Universidade Estadual Paulista, Marília, 2010.

OLIVEIRA, J. P.; BRAGA, T. M. S. Efeitos de um programa de intervenção com base em apoio pictográfico e consciência metatextual. In: CONGRESSO NACIONAL DE EDUCAÇÃO - EDUCERE, 9. Curitiba, 26 a 29 out. 2009. Anais eletrônicos... Curitiba: PUC, 2009. p. 6574-6586. Disponível em: <http://www.pucpr.br/eventos/educere/educere2009/anais/pdf/2560_1324.pdf>. Acesso em: 4 set. 2017.

OLIVEIRA, J.P.; ZABOROSKI, A.P. Interdisciplinary Practices along with the Basic Literacy Process: The Continuing Education Focused on Teachers. Creative Education, v. 06, p. 1815-1824, 2015.

PINTON, F.M. O ensino de produção textual escrita na revista Nova Escola: uma análise de discurso crítica. Veredas - Revista de Estudos Linguísticos, Juiz de Fora, v. 1, p. 338-344, 2011.

PROGRAMME FOR INTERNATIONAL STUDENT ASSESSMENT (PISA). BRAZIL -Country Note Results from PISA 2012. [S.1]: OCDE, [2013?]. Disponível em: <http://www.oecd.org/pisa/keyfindings/PISA2012-results-brazil.pdf>. Acesso em: 5 maio 2014.

REGO, L.L.B. Um estudo exploratório dos critérios utilizados pelas crianças para definir histórias. In: DIAS, M.G.B.; SPINILlO, A.G. (Orgs.). Tópicos em psicologia cognitiva. Recife: Universidade Federal de Pernambuco, 1996. p. 120-138.

RODRIGUES, M. do R. de F.; VILELA, F.C. Resolução da situação-problema e desfecho em histórias de crianças de 7 e 9 anos. Psicologia: Ciência e profissão, v. 32, n. 2, p. 422-437, 2012.

ROMANO-SOARES, S.; SOARES, A.J.C.; CÁRNIO, M.S. Práticas de narrativas escritas em estudantes do ensino fundamental. Pró-Fono Revista de Atualização Científica, v. 22, n. 4, p. 379-384, out./dez. 2010.

SÃO PAULO (município). Secretaria Municipal de Educação. Diretoria de Orientação Técnica. Orientações curriculares e proposição de expectativas de aprendizagem para o Ensino Fundamental: ciclo I. São Paulo: SME/DOT, 2007, 208p.

SPINILLO, A.G.; MARTINS, R.A. Uma análise da produção de histórias coerentes por crianças. Psicologia: Reflexão e Crítica, v.10, p.219-248, 1997.

ZABOROSKI, A.P. O gênero de histórias e atividades metatextuais como recursos da prática pedagógica na produção de narrativas escritas. 2014. 163f. Dissertação (Mestrado em Educação) - Universidade Estadual do Centro-Oeste, Guarapuava, 2014.

ZABOROSKI, A.P.; OLIVEIRA, J.P. Ressignificação da prática pedagógica referente ao gênero de histórias. In: CONGRESSO NACIONAL DE FORMAÇÃO DE PROFESSORES, 2. CONGRESSO ESTADUAL PAULISTA SOBRE FORMAÇÃO DE EDUCADORES, 12. Águas de Lindóia/SP, 7 a 9 abr. 2014. Anais eletrônicos...São Paulo: Unesp, 2014. p. 10989-11001. Disponível em: <https://drive.google.com/file/d/0BygOX4KNX9_iX3pvVDNFRGg0Z2s/edit>. Acesso em: 4 set. 2017.

ZABOROSKI, A.P.; OLIVEIRA, J.P. Written narratives productions: a review of litterature emphasizing pedagogical practice. Distúrbios da Comunicação, v. 27, n. 3, p. 572-592, 2015. 


\section{Conceptions of teachers on their teaching practices using the narrative type before and after a metatextual intervention program}

\begin{abstract}
This article aims to identify, under the teachers conceptions, their pedagogical practices developed with the narrative type before and after a metatextual intervention program. Two teachers and 27 students from the 4th year of elementary school of two public municipal schools in the State of Parana participated in this study. The collaborative and purposeful research had 5 stages: a) investigation of the teacher's pedagogical practices using the narrative type; b) evaluation of the student's narrative scheme; c) holding meetings with teachers for study of the subject and an intervention proposal; d) intervention in the pedagogical practice focused on the production of narratives written by students; e) evaluation of the student's written narratives schemes and the proposed pedagogical practice. The data was collected in individual and semi-structured interviews with the teachers. The interviews were transcribed and analyzed through its contents, setting up thematic categories. The results indicated that the absence of structure domain and the organization of the narrative type interfered in the planning of pedagogical strategies. The educational practices developed were focused on the use of language, emphasizing the regulatory aspects of grammar. After developing the program, the practice directs its focus to the reflection on the language, including explicit instructions on the production of the narrative type. We conclude that a planned and short educational intervention favors pedagogical practice focused on the production of more elaborate and complete written narratives by students.
\end{abstract}

Keywords: Writing learning. Pedagogical practice. Assistance to schools.

\section{Concepciones de profesoras sobre sus prácticas pedagógicas utilizando el tipo textual narrativo antes y después de un programa de intervención metatextual}

\section{Resumen}

Este artículo tiene como objetivo identificar, en la concepción de las profesoras, sus prácticas pedagógicas desarrolladas con el tipo textual narrativo antes y después de un programa de intervención meta textual. Participan del estudio dos profesoras y 27 alumnos del $4^{\circ}$ año de la escuela primaria de dos escuelas públicas municipales del interior del Estado de Paraná. La investigación colaborativa e propositiva fue compuesta por cinco etapas: a) investigación de prácticas pedagógicas de las profesoras utilizando el tipo textual narrativo; b) evaluación del esquema de narrativa escrita de los alumnos; c) realización de encuentros con las profesoras para el estudio del tema y de una propuesta de intervención; d) intervención en la práctica pedagógica orientada a la producción de narrativas escritas por los alumnos; e) evaluación del esquema de narrativa escrita de los alumnos y de la práctica pedagógica propuesta. La colecta de datos consistió en entrevistas semiestructuradas e individuales realizadas con las profesoras. Las entrevistas fueron transcriptas y analizadas por medio de sus contenidos, estableciéndose categorías temáticas. Los resultados indicaron que la ausencia de dominio de la estructura y de la organización del tipo textual narrativo interfería en la planificación de las estrategias pedagógicas. Las prácticas pedagógicas desarrolladas eran orientadas al uso del lenguaje, poniendo énfasis en los aspectos normativos de la gramática. Después del desarrollo del programa las prácticas ha direccionado su foco para la reflexión sobre el idioma y el lenguaje, abarcando instrucciones explicitas sobre la producción del tipo textual narrativo.

Palabras-clave: aprendizaje de la escritura. Práctica pedagógica. Asesoría a las escuelas. 


\section{Ana Paula Zaboroski}

E-mail: anapaulazaboroski@yahoo.com.br

\section{Jáima Pinheiro Oliveira}

E-mail: jaima@marilia.unesp.br

\section{Aliandra Cristina Mesomo Lira}

E-mail: aliandralira@gmail.com
Enviado em: 27/11/2015

Versão final recebida em: 07/04/2017

Aprovado em: 17-04-2017 